\title{
Memfungsikan Kembali (Refunction) Kali Gedeg Sebagai Short Cut Pengendali Banjir DAS Kali Marmoyo
}

\author{
Choirul Anwar, Kuntjoro, Sukobar, Didik Harijanto \\ Program Studi Diploma Teknik Sipil FTSP ITS, Surabaya \\ Email: choir_war@ce.its.ac.id
}

\begin{abstract}
Marmoyo River overflow is almost every year inundated Plandaan, Ploso, Kudu, Gedeg, Kemlagi, and Jetis sub-districts. Marmoyo River flood control by means river normalization contains a risk that discharge flood load to the Jagir Wonokromo Canal will be high. This paper discusses proposed construction of short cut from the Marmoyo River to the Brantas River through the Gedek River by considering: The degradation of Brantas River bottom in down stream of The Menturus rubber dam has reached 5.0 meters, and The condition of Gedek Irrigation Area intake is hang 2.10 metres above of Brantas flood water level.Thus it is very possible to build the short cut from Marmoyo River to Brantas River.
\end{abstract}

Keywords: Flood, Short Cut, Marmoyo River.

\section{Abstrak}

Luapan banjir Kali Marmoyo hampir setiap tahun menggenangi sebagian wilayah kecamatan Plandaan, Ploso, Kudu, Gedeg, Kemlagi, dan Jetis. Pengendalian banjir Kali Marmoyo dengan cara normalisasi sungai mengandung resiko bahwa beban debit banjir yang akan ditanggung oleh Kali Jagir Wonokromo akan semakin besar. Solusi yang diajukan dalam makalah ini adalah membuat short cut dari kali Marmoyo ke Kali Brantas melalui Kali Gedek, dengan pertimbangan degradasi dasar kali Brantas di Down Stream Dam Karet Menturus mencapai 5 meter, dan kondisi intake DI Gedek menggantung 2,10 meter pada saat banjir Kali Brantas. Dengan demikian sangat memungkinkan sudetan dari Kali Marmoyo ke Kali Brantas.

Kata kunci: Banjir, Short Cut, Kali Marmoyo.

\section{Pendahuluan}

DAS Kali Marmoyo terletak pada posisi $12^{\circ} 29^{\prime}$ 0,676" Bujur Timur dan $7^{\circ} 24^{\prime}$ 37,415" Lintang Selatan, dimana Kali Marmoyo berawal dari Gunung Marmoyo mengalir ke arah timur melewati perkampungan dan daerah pertanian yang cukup subur dan bermuara pada Kali Surabaya. Di mana Kali Surabaya sendiri adalah cabang Kali Brantas. Secara administratif berada di kabupaten Jombang dan kabupaten Mojokerto (PT. Resco, 2003).

Kali Marmoyo adalah salah satu anak sungai Brantas, dengan luas Daerah Aliran Sungai (DAS) $289.72 \mathrm{~km}^{2}$ dan panjang sungai $44.32 \mathrm{~km}$ yang terletak di sebelah utara Kali Brantas (Nippon, 1993). Luapan banjir Kali Marmoyo hampir setiap tahun menggenangi sebagian wilayah kecamatan Plandaan, Ploso, Kudu, Gedeg, Kemlagi, dan Jetis. Daerah yang tergenang banjir di Kecamatan Jetis sebagian besar merupakan daerah permukiman. Sedangkan di bagian hulu, daerah yang tergenang adalah daerah pertanian yang cukup subur dengan luas daerah irigasi mencapai 5.500 ha (PT. Resco, 2003).

Usaha pemerintah untuk mengatasi banjir telah diadakan yaitu perbaikan secara darurat pada bagian hilir berupa

Jurnal APLIKASI: Media Informasi \& Komunikasi Aplikasi Teknik Sipil Terkini Halaman 27 
pengendalian banjir dimulai dari kecamatan Jetis sampai Kecamatan Ploso. Hal ini dilakukan untuk menanggulangi banjir rutin setiap tahun yang melanda daerah permukiman dan pertanian di 5 (lima) wilayah kecamatan, namun dengan usaha tersebut hingga saat ini banjir yang terjadi masih belum teratasi (PT. Resco, 2003). Untuk mengatasi banjir secara tuntas, efektif, dan ekonomis berdasarkan peninjauan kondisi banjir yang terjadi pada tahun 2002, telah dilakukan perencanaan penanganan banjir berupa normalisasi Kali Marmoyo mulai dari Desa Jetis hingga Desa Kupang, Kecamatan Jetis (PT. Resco, 2003).

Pengendalian banjir Kali Marmoyo dengan normalisasi sungai diutarakan di atas mengandung resiko bahwa beban debit banjir yang akan ditanggung oleh Kali Surabaya akan semakin besar. Dengan demikian solusi tersebut akan berakibat pada beban lebih (over capacity) pada Kali Jagir Wonokromo yang merupakan saluran pembuang terakhir Kali Surabaya. Dengan demikian diperlukan solusi alternatif untuk menghindarkan over capacity Kali Surabaya terutama Kali Jagir Wonokromo.

\section{Metodologi}

\subsection{Kondisi Umum Sungai}

Kali Marmoyo merupakan sungai dengan kemiringan yang relatif datar. Ruas Kali Km 0.00 - Km 7.413 bentuk penampang beraturan dilengkapi bantaran dan tanggul banjir. Ruas Kali $\mathrm{Km}$ 7.413 - Km 14.100 bentuk penampang cukup beraturan tanpa bantaran dan tanggul banjir. Ruas km 14.00 - Km 16.613 bentuk penampang cukup beraturan tanpa bantaran dan tanggul banjir (PT. Resco, 2003). Melewati daerah permukiman (Desa Barat Kulon). Ruas $\mathrm{Km} 16.613$ - Km 18.485 bentuk penampang cukup beraturan tanpa bantaran dan tanggul banjir, sebelah kanan dan kiri Kali merupakan saluran sekunder Mernung. Ruas Km. 18.485 - Km. 20.373 bentuk penampang cukup beraturan tanpa bantaran dan tanggul banjir, sebelah kanan dan kiri Kali merupakan saluran sekunder Mernung (Nippon, 1988, 1992; Kuntjoro, 2013).

Tata guna lahan DAS Kali Marmoyo terdiri dari lahan pertanian, lahan kering, tegalan, dan perkampungan. Sistem sungai Kali Marmoyo dan anakanak sungainya dapat dilihat pada Gambar 1 (PT. Resco, 2003).

\subsection{Kondisi Debit Banjir}

Kondisi hidrologis hidrologis Kali Marmoyo dan anak-anak sungainya yang dianalisis dari data debit yang tercatat ditunjukkan pada Tabel 1 . sedangkan debit harian maksimum di Kali Marmoyo sendiri seperti yang ditunjukkan pada Tabel 2.

Debit banjir rencana dianalisis dari data curah hujan yang tercatat selama 18 tahun yaitu stasiun penakar hujan Ploso, Kabuh, Tapen, dan Gedeg. Hasil analisis debit banjir rencana untuk Kali Marmoyo dan anak-anak sungainya ditunjukkan pada Tabel 3. Dan debit maksimum untuk anak-anak Kali Surabaya ditunjukkan pada Tabel 4. 


\section{ISSN.1907-753X}

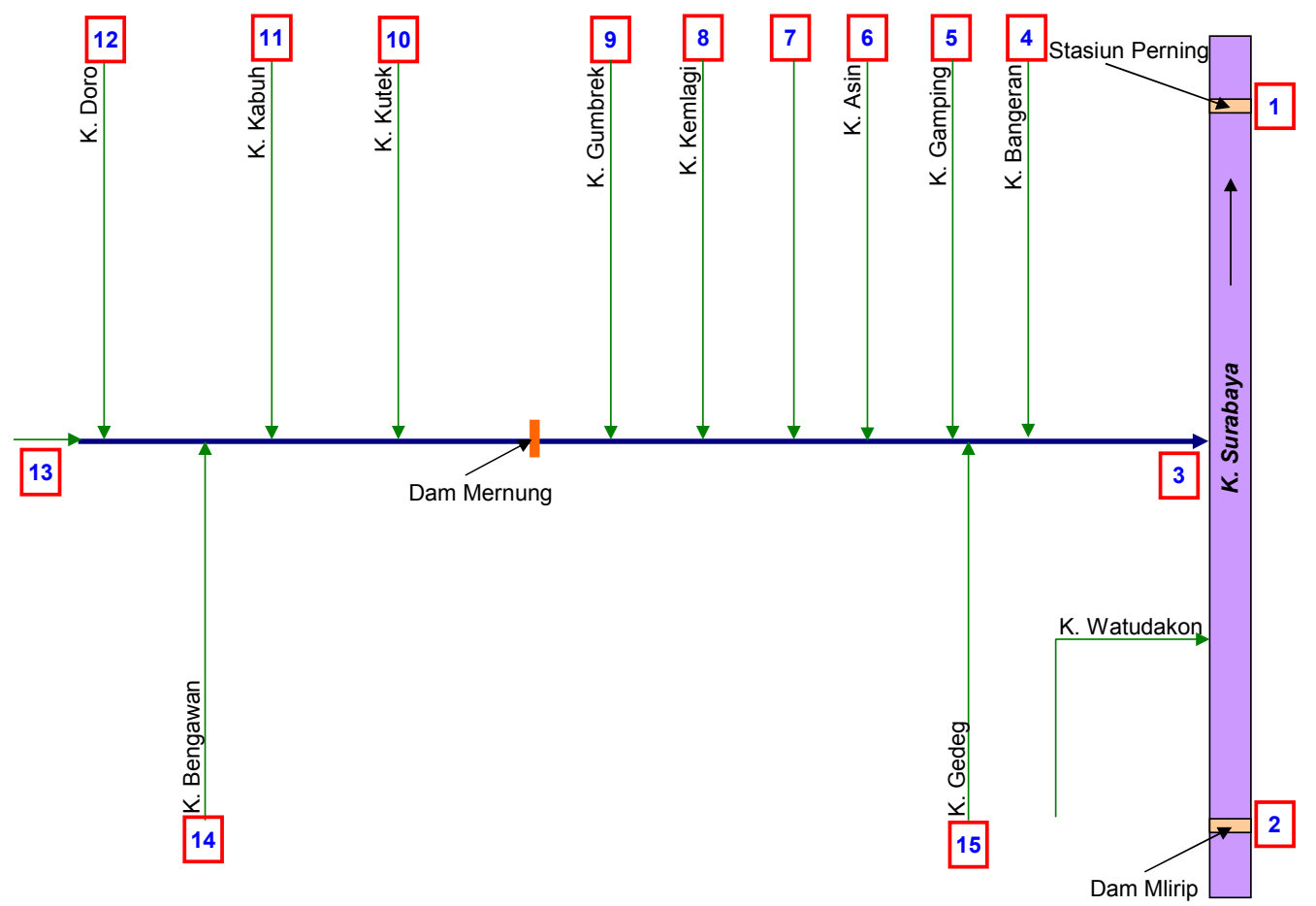

Gambar 1. Sistem Sungai Kali Marmoyo

Tabel 1. Debit Harian Maksimum Sungai Marmoyo dan Anak Sungainya $\left(\mathrm{m}^{3} / \mathrm{dt}\right)$

\begin{tabular}{|c|c|c|c|c|c|c|c|c|c|c|c|c|c|}
\hline \multirow{2}{*}{ Tahun } & \multirow{2}{*}{$\begin{array}{c}\text { Sungai } \\
\text { Marmoyo }\end{array}$} & \multicolumn{12}{|c|}{ Anak Sungai } \\
\hline & & Mernung & Bangeran & Gamping & Asin & Sukorejo & Kemlagi & Gumbrek & Kutek & Kabuh & Doro & Bengawan & Gedeg \\
\hline 1992 & 118,70 & 59,95 & 4,19 & 4,48 & 3,15 & 2,98 & 5,14 & 19,07 & 5,16 & 11,30 & 18,07 & 11,88 & 12,62 \\
\hline 1993 & 125,70 & 63,48 & 4,44 & 4,74 & 3,34 & 3,16 & 5,44 & 20,20 & 5,47 & 11,96 & 19,13 & 12,58 & 13,37 \\
\hline 1994 & 107,80 & 54,44 & 3,81 & 4,07 & 2,86 & 2,71 & 4,67 & 17,32 & 4,69 & 10,26 & 16,41 & 10,79 & 11,46 \\
\hline 1995 & 131,10 & 66,21 & 4,63 & 4,95 & 3,48 & 3,29 & 5,68 & 21,07 & 5,70 & 12,48 & 19,96 & 13,12 & 13,94 \\
\hline 1996 & 111,40 & 56,26 & 3,93 & 4,20 & 2,96 & 2,80 & 4,82 & 17,90 & 4,84 & 10,60 & 16,96 & 11,15 & 11,85 \\
\hline 1997 & 151,40 & 76,46 & 5,34 & 5,71 & 4,02 & 3,80 & 6,55 & 24,33 & 6,58 & 14,41 & 23,05 & 15,15 & 16,10 \\
\hline 1998 & 150,20 & 75,86 & 5,30 & 5,67 & 3,99 & 3,77 & 6,50 & 24,14 & 6,53 & 14,30 & 22,86 & 15,03 & 15,97 \\
\hline
\end{tabular}

Tabel 2. Debit Harian Maksimum Sungai Marmoyo $\left(\mathrm{m}^{3} / \mathrm{dt}\right)$

\begin{tabular}{|c|c|c|c|c|c|c|c|c|c|c|c|c|}
\hline \multirow[t]{2}{*}{ Tahun } & \multicolumn{12}{|c|}{ B u l a n } \\
\hline & Jan & Feb & Mar & Apr & Mei & Jun & Jul & Agust & Sep & Okt & Nop & Des \\
\hline 1992 & 76,6 & 118,7 & 97,8 & 70,3 & 55,7 & 4,3 & 9,9 & 3,9 & 20,4 & 3,7 & 10,6 & 64,7 \\
\hline 1993 & 125,7 & 105,5 & 34,8 & 42,3 & 24,1 & 5,6 & 6,3 & 3,1 & 2,0 & 1,0 & 27,7 & 43,3 \\
\hline 1994 & 69,7 & 78,6 & 107,8 & 46,7 & 62,2 & 12,3 & 6,9 & 8,9 & 4,3 & 4,6 & 4,2 & 24,1 \\
\hline 1995 & 75,0 & 101,8 & 131,1 & 110,5 & 17,3 & 62,7 & 20,4 & 5,1 & 3,1 & 52,0 & 85,3 & 41,5 \\
\hline 1996 & 65,9 & 111,4 & 77,3 & 59,0 & 7,4 & 5,4 & 6,3 & 3,9 & 2,5 & 2,6 & 45,8 & 62,9 \\
\hline 1997 & 100,7 & 151,4 & 27,8 & 79,5 & 0,0 & 4,4 & 1,4 & 1,2 & 1,0 & 2,2 & 1,7 & 47,4 \\
\hline 1998 & 35,4 & 150,2 & 122,1 & 26,2 & & & & & & & & \\
\hline
\end{tabular}

Jurnal APLIKASI: Media Informasi \& Komunikasi Aplikasi Teknik Sipil Terkini Halaman 29 
Tabel 3. Debit Banjir Rencana Sungai Marmoyo dan Anak Sungainya ( $\left.\mathrm{m}^{3} / \mathrm{dt}\right)$

\begin{tabular}{|c|c|c|c|c|c|c|c|c|c|c|c|c|c|}
\hline \multirow{2}{*}{$\begin{array}{c}\text { Perode } \\
\text { Ulang }\end{array}$} & \multirow{2}{*}{$\begin{array}{c}\text { Sungai } \\
\text { Marmoyo }\end{array}$} & \multicolumn{12}{|c|}{ Anak Sungai } \\
\hline & & Mernung & Bangeran & Gamping & Asin & Sukorejo & Kemlagi & Gumbrek & Kutek & Kabuh & Doro & Bengawan & Gedeg \\
\hline 5 & 112,03 & 56,58 & 3,95 & 4,23 & 2,97 & 3,80 & 4,85 & 18,00 & 4,87 & 10,66 & 17,05 & 11,21 & 11,91 \\
\hline 10 & 124,69 & 62,97 & 4,40 & 4,71 & 3,31 & 4,23 & 5,40 & 20,04 & 5,42 & 11,87 & 18,98 & 12,48 & 13,26 \\
\hline 25 & 140,68 & 71,05 & 4,97 & 5,31 & 3,73 & 4,78 & 6,09 & 22,61 & 6,12 & 13,39 & 21,41 & 14,08 & 14,96 \\
\hline 50 & 152,55 & 77,04 & 5,38 & 5,76 & 4,05 & 5,18 & 6,60 & 24,51 & 6,63 & 14,52 & 23,22 & 15,26 & 16,22 \\
\hline 100 & 164,32 & 82,99 & 5,80 & 6,20 & 4,36 & 5,58 & 7,11 & 26,41 & 7,15 & 15,64 & 25,01 & 16,44 & 17,47 \\
\hline
\end{tabular}

Tabel 4. Debit Banjir Rencana Anak-anak Sungai Kali Surabaya $\left(\mathrm{m}^{3} / \mathrm{dt}\right)$

\begin{tabular}{ccccc}
\hline \multirow{2}{*}{$\begin{array}{c}\text { Perode } \\
\text { Ulang }\end{array}$} & \multicolumn{4}{c}{ Anak Sungai } \\
\cline { 2 - 5 } & Mlirip & $\begin{array}{c}\text { Watu } \\
\text { Dakon }\end{array}$ & Perning & Marmoyo \\
\hline 5 & 108,96 & 39,31 & 188,28 & 112,03 \\
10 & 135,39 & 43,75 & 205,93 & 124,69 \\
25 & 168,79 & 49,36 & 228,24 & 140,68 \\
50 & 193,57 & 53,53 & 244,78 & 152,55 \\
100 & 218,16 & 57,66 & 261,21 & 164,32 \\
\hline Sumber: PT. Resco, 2003 & &
\end{tabular}

\section{Hasil dan Pembahasan}

\subsection{Alternatif 1 Normalisasi Kali Marmoyo}

Normalisasi Kali Marmoyo seperti yang disebut pada pendahuluan, mengandung resiko pada beban lebih pada kapasitas kali Jagir Wonokromo. Pada tahun 2002 terjadi banjir yang cukup signifikan hingga meluap ke daerah-daerah permukiman terutama di daerah Medokan Semampir dan Wonorejo, sehingga pada tahun 2003 dilakukan review debit rencana oleh Tim Kajian Teknis Design Capacity untuk Kali Jagir Wonokromo yang didasarkan data historis pengamatan banjir 1991 - 2003 didapat $\mathrm{Q}_{25}$ sebesar $419 \mathrm{~m}^{3} /$ det yang semula $\mathrm{Q}_{25}$ adalah $379 \mathrm{~m}^{3} /$ detik (bbwsbrantas.com, 2011).

Pada tahun 2007 telah terbit Peraturan Dearah Propinsi Jawa Timur Nomor 9 tentang penataan sempadan sungai Kali Surabaya dan Kali Wonokromo. Berda- sarkan perda tersebut maka telah dilakukan penertiban bersama antara Pemerintah Propinsi, Kota Surabaya Perum Jasa Tirta I dan Balai Besar Wilayah Sungai (BBWS) Brantas pada permukiman liar disepanjang jembatan Jagir sampai jembatan Nginden dan di kawasan Wonorejo. Meningkatkan kapasitas sungai sehingga mampu mengalirkan debit banjir rencana $\mathrm{Q}_{25}=419$ $\mathrm{m}^{3}$ /dtk (Nippon, 1988, 1992; Kuntjoro, 2013).

Dalam keadaan debit banjir besar di Kali Brantas, debit banjir dialirkan ke Porong kanal dengan jalan menutup pintu air Mlirip. Dengan demikian debit banjir dari Kali Brantas tidak mengalir masuk ke Kali Surabaya. Namun demikian Kali Surabaya tetap menanggung debit banjir dari anak-anak sungainya (Kali Mlirip, Watu Dakon, Perning, dan Marmoyo). Debit banjir anak-anak sungai Kali Surabaya tersebut ditanggung oleh Kali Jagir Wonokromo. Debit yang mengalir dari anak-anak sungai Kali Surabaya ini terakumulasi menjadi debit banjir Kali Jagir Wonokromo, ditunjukkan pada Tabel 5.

Tabel 5. Debit Banjir Rencana Kali Jagir Wonokromo Setelah Normalisasi Kali Marmoyo

\begin{tabular}{cccccc}
\hline Perode Ulang & 5 & 10 & 25 & 50 & 100 \\
\hline $\begin{array}{c}\text { Debit } \\
(\mathrm{m} 3 / \text { detik })\end{array}$ & 448,59 & 509,77 & 587,08 & 644,42 & 701,35 \\
\hline
\end{tabular}


Dengan kondisi debit banjir rencana yang ditunjukkan pada Tabel 5 tersebut maka kapasitas Kali Jagir Wonokromo tidak mampu mengalirkan debit dengan periode ulang 5 tahun.

3.2. Alternatif 2 Short Cut Kali Marmoyo Ke Kali Brantas Melalui Kali Gedeg

Alternatif 2 ini dilakukan atas pertimbangan-pertimbangan:

1. Meninjau kondisi debit banjir recana yang mengalir di Kali Surabaya yang terakumulasi dari Kali Marmoyo, Kali Perning, Kali Watudakon, dan Kali Mlirip yang kemudian di bagian hilir ditambah debit dari waduk Wiyung. Hal ini menyebabkan kapasitas Kanal Jagir Wonokromo tidak mencukupi.

2. Dasar Kali Brantas di down stream Dam Karet Menturus semakin menurun, sehingga memungkinkan untuk membangun sudetan (short cut) dari Kali Marmoyo menuju Kali Brantas melalui kali Gedek. Seperti yang ditunjukkan pada Gambar 2.

Kondisi geometri Kali Brantas pada dekade terakhir ini banyak mengalami perubahan, terutama pada segmen Mojokerto, sehingga banyak intake irigasi yang tidak bisa mengalirkan air secara gravitasi sesuai dengan perencanaan semula (Kuntjoro, 2013).

Sebagai contoh adalah intake DI Gedek seperti yang terlihat pada Gambar 3 menggambarkan kondisi intake irigasi pada Tahun 1992, Gambar 4 menggambarkan kondisi tahun 2011 dan Gambar 5 foto intake pada kondisi tahun 2012 (Kuntjoro, 2013). Dengan kondisi intake DI Gedek menggantung 2,1 meter pada saat banjir Kali Brantas sperti yang terlihat pada Gambar 3, Gambar 4, dan Gambar 5, maka memungkinkan sudetan dari Kali Marmoyo ke Kali Brantas.

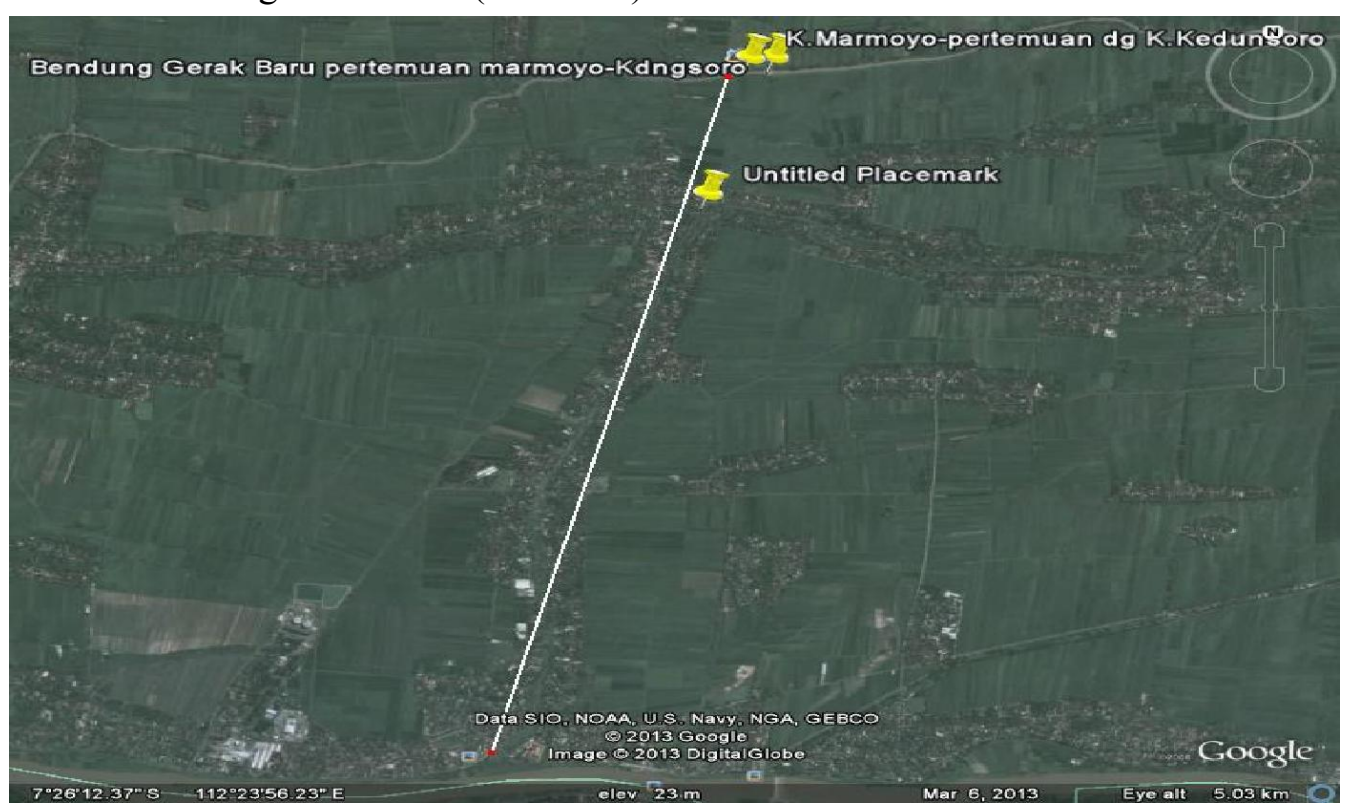

Gambar 2. Jalur Short Cut Kali Marmoyo Ke Kali Brantas

Jurnal APLIKASI: Media Informasi \& Komunikasi Aplikasi Teknik Sipil Terkini Halaman 31 


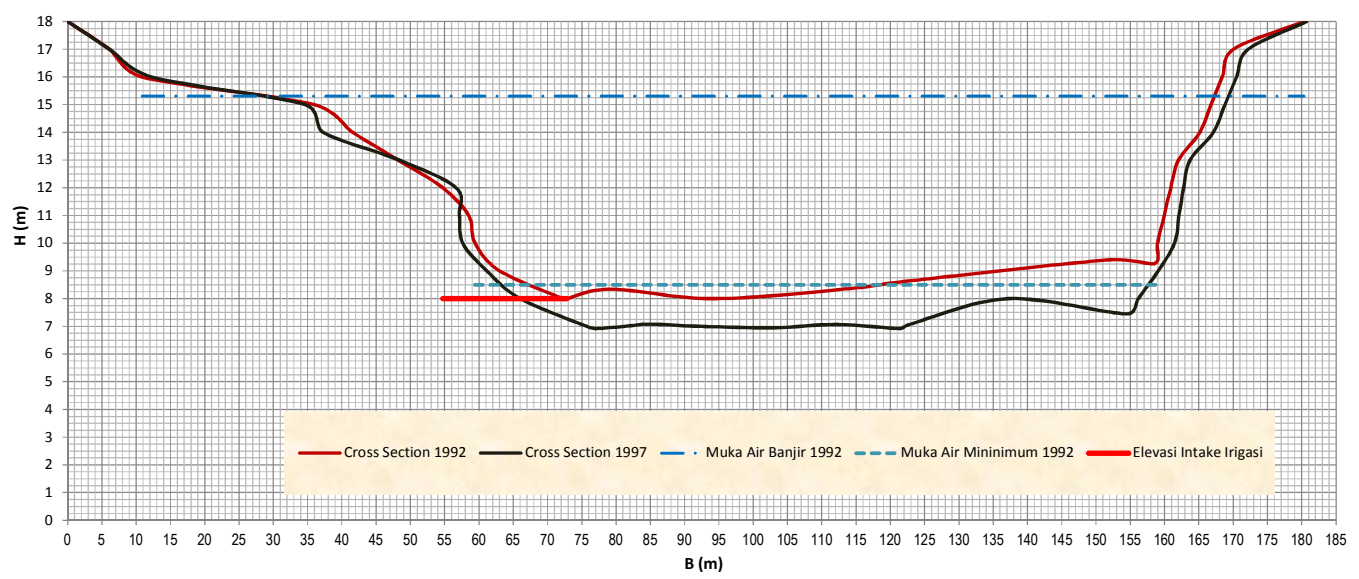

Gambar 3. Posisi Intake Saluran Irigasi Gedek Dari Kali Brantas Tahun 1992

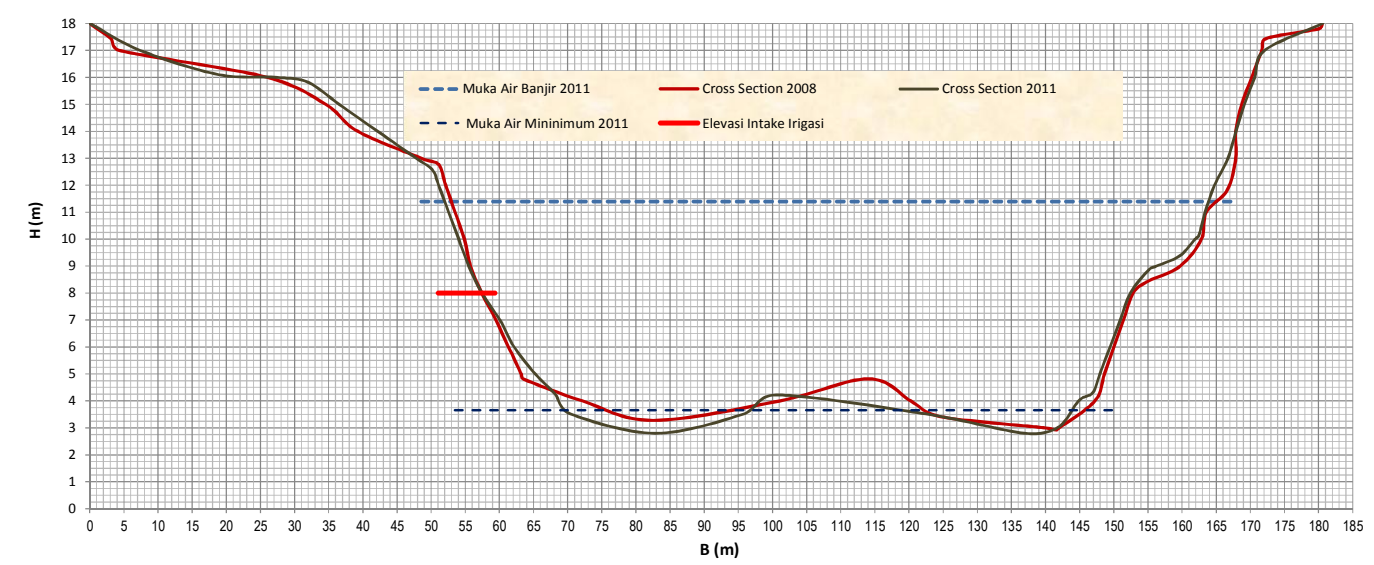

Gambar 4. Posisi Intake Saluran Irigasi Gedek Dari Kali Brantas Tahun 2011

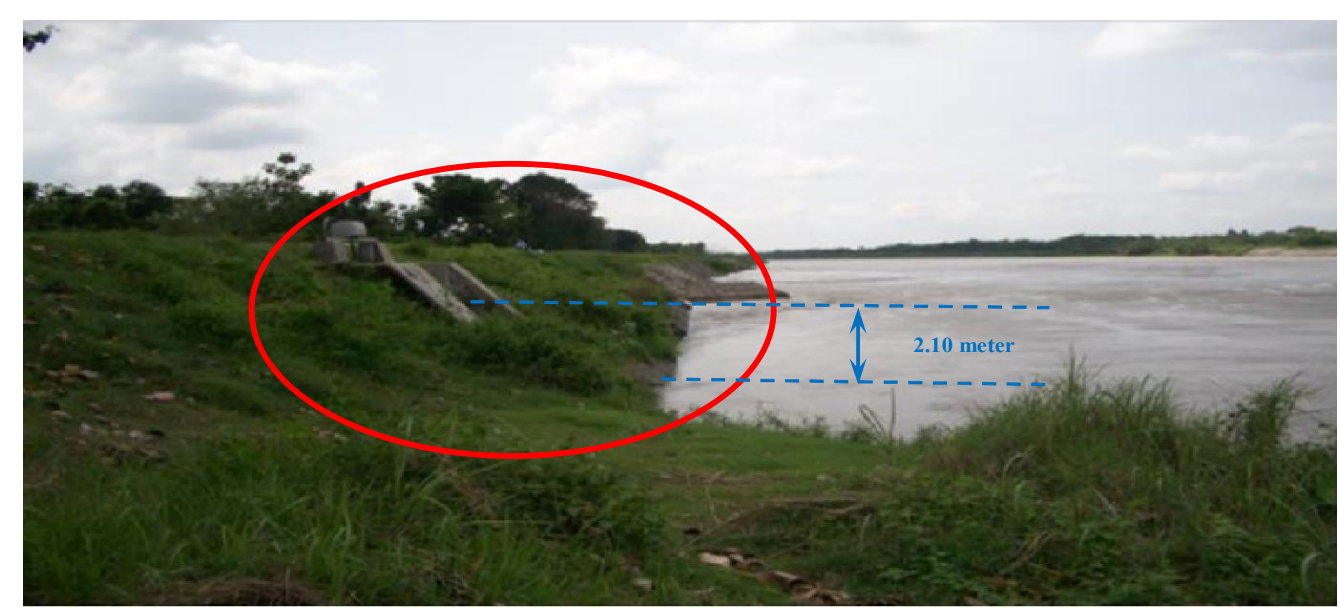

Gambar 5. Foto Posisi Intake Saluran Irigasi Gedek Dari Kali Brantas Tahun 2012 Dalam Kondisi Banjir

Halaman 32 Jurnal APLIKASI: Media Informasi \& Komunikasi Aplikasi Teknik Sipil Terkini 


\section{Simpulan}

- Kapasitas Kali Jagir Wonokromo tidak mampu mengalirkan debit dengan periode ulang 5 tahun.

- Degradasi dasar kali Brantas di Down Stream Dam Karet Menturus mencapai 5 meter.

- Kondisi intake DI Gedek menggantung 2,10 meter pada saat banjir Kali Brantas.

- Memungkinkan sudetan dari Kali Marmoyo ke Kali Brantas melalui kali Gedeg.

\section{Daftar Pustaka}

Isgiyanto. 2011. "Beruntungnya Surabaya Memiliki Kali Wonokromo," http://bbwsbrantas.com/indeks, [Online], 20 Juni.

Kuntjoro, Didik Harijanto, Sungkono, Saptarita, Choirul Anwar. 2013. "Perkiraan Geometri Sungai Bermeander dari Besaran Debit," Jurnal APLIKASI ISSN.1907753X Volume 11, Nomor 1, Pebruari.

Kuntjoro, Choirul Anwar, Pudiastuti, Didik Harijanto, Sungkono. 2013. "Inisiasi Perkiraan Arah Pergerakan Alur Sungai" Jurnal APLIKASI ISSN.1907-753X Volume 11, Nomor 2, Agustus.

Kuntjoro, C. Anwar and D. Harijanto. 2013. "Impacts of River Groove Propagation on Irrigation Infrastruktural Failures," IPTEK, Journal of Proceeding Series, vol. 1, no. ITS.

Nippon Koei Co and PT. Indra Karya. 1988. Report on Additional River Improvement Plan for the Upper Part of Brantas Middle Reaches, OECF Loan, November.

Nippon Koei Co. 1992. Final Report on Special Asistance for Project
Sustainability (SAPS-II) on Brantas River Basin Development Project, OECF, March.

Nippon Koei Co. 1993. Completion Report on River Improvement Works, OECF, December.

PT. Resco Nusantara Konsultan. 2003. Laporan Akhir SID Normalisasi Sungai Marmoyo di Kabupaten Mojokerto.

Jurnal APLIKASI: Media Informasi \& Komunikasi Aplikasi Teknik Sipil Terkini Halaman 33 
